doi: 10.17492/manthan.v3i1.6599

\title{
Growth Drivers and Trends of E-wallets in India
}

\author{
Navdeep Kumar*
}

\begin{abstract}
The present paper is an endeavour to underline the technology led revolution in online payments with the advent of e wallets in India. The key focus of the present paper is on highlighting the growth factors and trends regarding use of e wallets in India. In order to make India a rising international player for sustainable market development, financial inclusion of the rural population will be decisive. E-wallet possesses the prospective as a largest player for making e-transactions in India. However, to enhance the popularity and usage of e wallets, there are certain pre requisites such as adequate infrastructure and comfortable user experience.
\end{abstract}

Keywords: Online payments, E-wallet, Financial inclusion.

\subsection{Introduction}

E-wallet refers to a wallet for making instantaneous payments with the use of a smart phone, also known as digital or mobile wallet, which is emerging as quite effective mode of payments in the wave of e-commerce and enhanced mobile usage. In the present era, smart phone has become imperative in every walk of life owing to its utility as well as facility. Besides a communication device, it is widely used as social, entertainment internet access and payment tool (Rajgopal, 2012).

It is a prepaid payment application mode on a mobile phone where firstly cash is deposited like placing in a wallet and thereafter transactions are carried out without cash or card. Even a customer without a bank account can make use of e-wallet for making online payments. Moreover, it does not require internet access as in the case of online banking. Making payment through such mode is quite convenient and efficient as compare to the conventional mode of payments.

*Assistant Professor, PG Department of Commerce and Business Administration, Lyallpur Khalsa College, Jalandhar, Punjab

(e-mail: Email-navdeepgandotra@yahoo.com) 
In order to make India as rising international player for sustainable market development, financial inclusion of the rural population will be decisive. E-wallet possesses the prospective as a largest player for making e- transactions in India. It would be a great facilitator for the accomplishments of financial inclusion goals particularly among rural population. However, to enhance the popularity and usage of e wallets, there are certain pre requisites such as adequate infrastructure and comfortable user experience.

In the light of above perspective, the present paper focuses on the key growth drivers, trends, potential and challenges of e-wallets in the Indian market. Besides, introduction in Section 1, the evolutionary trends of e-wallets have been discussed in Section 2. Section 3 overviews the types and trends of e-wallets in India. The key issues of concern relating to the usage of e wallets have been elaborated in section 4 . The conclusion and suggestions have been elucidated in Section 5.

\subsection{Evolution and Growth of E-wallet}

The global surge towards electronic payment system owing to the technological advancement assists to pay online resulting into increased effectiveness, better safety and enhance customer expediency (Abor, 2004). According to Kalakota \& Whinston (1997), electronic payment is a financial exchange that takes place online between the buyer and the seller. The content of this exchange is usually the form of digital financial instrument such as encrypted credit card numbers, electronic checks, or digital cash that is backed by a bank or an intermediary, or by a legal tender. In other words, payment by direct credit, electronic transfer of credit card details, or some other electronic means, as opposed to payment by cheque and cash covers under e-payments (Agimo, 2004). The following are the limitations of traditional payment, owing to which e payments are considered more quick and reliable:-

- Low efficiency.

- Time consuming.

- Less reliable.

- No Immediate response.

- More paper work

Consequently, E-wallet allows users to make electronic commerce transactions quickly and securely through electronic accounts maintained on mobile phones for making payments. The enhanced acceptance and usage of smart phones has drastically transformed the mode of payments. The expansion of the global mobile market has augmented by the competitive market as well as online payments. 
The rise in e-commerce offers the facility of buying and selling products, information and services via online. The concern of secure and dependable money swap is important. In e-commerce milieu, payments are carried out in an electronic form called electronic Payments (Abrazhevich \& Markopoulos, 2009). E-wallet is coined from the term Digital Wallet invented by Sam Pitroda, founder of Digital Wallet in 1996. They advocated that digital wallet would consist of a liquid crystal display not much bigger than a regular plastic bank card, which preferably a touch-sensitive screen and simple user interface that lets the user flip through the digital wallet in the same manner he/she flips through a leather wallet (Pitroda and Desai, 2010).

\subsection{The ecosystem of mobile wallet}

There are two possible points of view when we look at the ecosystem of the mobile wallet. In terms of technology and it is based on the founder point of view, Pitroda introduced in detail the mobile wallet ecosystem (Pitroda S., Desai M., 2010) Further, In the GSMA White Paper, mobile wallet was defined as "a software application on a mobile handset that function as a digital container for payment cards, tickets, loyalty cards, receipts, vouchers and other items that might be found in a conventional wallet. The mobile wallet enables the user to manage a broad portfolio of mobile NFC [Near Field Communication] services from many different companies" (GSMA, 2012).

In India, e-wallets are legally recognised as pre-paid payment instruments. As per the RBI guidelines, pre-paid payment instruments are issued under the Payment and Settlements Systems Act, 2005 and that facilitate purchase of goods and services, including funds transfer, against the value stored on such instruments. Such instruments can be issued as smart cards, magnetic stripe cards, internet accounts, internet wallets, mobile accounts, mobile wallets, paper vouchers and any such instrument which can be used to access the pre-paid amount. Unlike other pre-paid payment instruments, e-wallet is only an internet based online account, sans the existence of a physical card.

The companies incorporated in India with minimum paid-up capital of Rs. 500 lakh and minimum positive net worth of Rs. 100 lakh at all the times are allowed to issue wallets in India. Banks that fulfill with the eligibility criteria are allowed to issue all categories of wallets. However, only those banks which have been permitted to provide Mobile Banking Transactions by the RBI are permitted to launch mobile based wallets. RBI has also given authorization to certain entities to open payments banks and small finance banks. The basic idea is to further the process of financial inclusion. These banks in the coming years are expected to make a significant transformation in online transactions by popularising mobile payments through e-wallets in rural areas. 


\subsection{Facilities of E-wallet}

The followings are the facilities provided by the e wallets:-

- Easy to make payments and receipts both at national and international levels.

- Functioning or operation through mobile phone.

- Easy and faster access.

- Instant and direct confirmation of the transaction.

- Secure and Reliable.

Thus, E-wallet is created on smart phone as a leather wallet. As an alternate for the conventional wallet, an E-wallet provides huge possibilities as an instrument of financial inclusion.

\subsection{Growth drivers of E-wallets}

The growth of e wallets is attributed to the factors given below:-

- Growth of e-commerce

- Enhanced use of mobile phones

- Quick and safe mode of payment

- User friendly

- More convenient for the customers.

\subsection{Types and Trends of E-Wallet}

E-wallets fall in the category of prepaid payment instruments that facilitates online payments through the access to the pre-paid amount. Generally, mobile wallets are issued by banks or by approved non-banking institutions. Wallets issued by banks have the benefit in terms of fund transfer limits and cash withdrawals. Mobile wallet allows the customer to withdraw cash through agents, retailers, and ATMs. On the other hand, wallets issued by non-banking institutions do not provide cash withdrawal options. Open wallet issued by a bank charge fee to make active a mobile wallet. On the other hand, no charge is imposed for opening a semi-closed mobile wallet by non-banking institution. For bank-issued wallets, there could be other charges based on the nature of transactions. On the contrary, semi-closed wallet providers charge only for filling the money into the wallet and involve no charges for transfers or payments.

E wallets can be classified as follows:-

Closed $\boldsymbol{E}$-wallets - A closed E-wallet is issued by a company to its customers for facilitating purchase of goods or services solely from that company. Such E wallet does not allow cash withdrawal or redemption. For example, companies like myntra.com, Flipkart.com, Jabong.com etc. provides the facility of such type of $\mathrm{E}$ 
wallets. They provide cash backs for payments made through this channel. This is one way of ensuring loyalty of their customers. As these instruments do not facilitate payments and settlement for third party services, issue and operation of such wallets are not classified as payment systems. Hence, RBI approval is not required for issuing them. Semi-closed $\boldsymbol{E}$-wallets - A semi closed E Wallet provides the facility to make payments in a specific group of identifiable merchants for purchase of goods and services. Cash withdrawal and redemption is not allowed. These wallets do not permit cash withdrawal or redemption by the holder.Wallets for amounts upto Rs.10,000/- can be created under this category by accepting minimum details of the customer, provided the amount outstanding at any point of time does not exceed Rs. 10,000/- and the total value of reloads during any given month also does not exceed Rs. 10,000/-. Mobikwik, PayTM, PayUMoney Oxigen, QwikCilver Solutions etc. are the E wallets providers in this category.

Open E-wallets - An open e wallet can be used both for purchase of goods/services and executing financial services such as funds transfer and withdrawal of cash through ATMs. The ICICI bank has issued M-pesa with the collaboration of Vodafone in this segment.

Semi-open wallets - A semi open E Wallet is used by any vendor who accept card based payments through 'point of sales' machines. Such wallets do not permit cash withdrawal and redemption. E.g. gift cards issued by banks covers in this category.

\subsection{Processing of transaction via E-wallet}

The transaction through E- wallet can be processed in both forms i.e. online transaction and offline transaction.

Online Transaction: In this mode, the merchant attach the terminal to transfer the value collected in the terminal to his bank account. The terminal gives a message for each transaction to the e-Wallet host system, recognizing the card number and issuer and the amount. The host system debits the account of the issuer and credits the merchant's account. In this way, online transaction through $\mathrm{E}$ wallet is completed immediately.

Offline Transaction: In this option, a customer selects his or her purchase and approaches the payment portal. Thereafter, the merchant computes the value of purchase and enters it on the payment terminal that displays the amount and the cardholder after confirmation makes the payment within faction of seconds which is transferred from the e-Wallet to the terminal.

\subsection{Trends and future prospects of e wallets in India}

In a short span of time, e wallet market in India has grown considerably. The growth of e commerce and mobile commerce fuelled the expanded use of e wallet for 
making online payments with the enhanced use of smart phones. Owing to the innovative technological advancement online payment system has gained significant recognition as well as acceptance owing to the convenience, instant and safety.

The digital revolution has transformed the economy into digital economy that led to the surge in digital payments. According to a study by Ken Research, by 2019, Indian payment market is estimated to reach about 8173 billion comprising mobile wallet, mobile banking, point of sale mode etc.

To support further, another study report of CRISIL expects compound annual growth around $11-13 \%$ by payment banks in the next five years. It is also estimated that more than 400 million people in India will use the internet surpassing the US to become second largest web use after China. At present there are 10-15 e wallets companies are operating in India having more than 20 million active users, higher than the cumulative number of credit cards in India. Indians are already the second highest e- wallet users in Asia-pacific, second after China (Chakraborty, 2015). The competition in this area is growing. First, it was Google, then IT companies like Oxigen, and now banks (ICICI Bank, Axis, and SBI etc.), telecom firms (Airtel), and many start-ups have started operation in this area. Sometimes, even big shops and chains provide e-Wallet to its customers. In view of the future competition, many existing banks are offering e-Wallet facilities with different options. We have already seen Axis Bank and ICICI bank's eWallet schemes. HDFC announced earlier this year that they have big plans to go digital and launch e-Wallet services. In fact, most of the banks, in association with telecom firms, will come out with e-Wallet solution soon. For now, only a handful of banks are providing this with limited services.

The players in the e-commerce sector also advocated the increased use and awareness regarding e wallets in India. The most significant advantage besides online payment is to make refund to the customer more quickly and conveniently. It also reduces the cost of transaction of e-commerce companies on this account. Moreover the success rate of using e-wallet for payment is about $99 \%$ whereas in other mode, it is about $65 \%$. Use of e-wallets particularly facilitates e-commerce as customers are not required to fill out order forms at each site when they purchase an item as the information has already been stored and is automatically updated and entered in the order fields across merchant sites.

The e wallet market is also proving a boon for achieving the goals of financial inclusion. The evolution of payment banks along with the e wallet providers would enhance banking access to the common man by spreading drive towards cashless transactions in the remote areas of the country. 


\subsection{Key Issues and Concerns}

The E-wallet market is in a budding stage and use of e-Wallet is still in its formative stage. The concept is evolving with entrance of more players and new types of e-wallets. Despite of the benefits and enlarged use of e wallets, there are certain key issue of concern that needs to be carefully examined and addressed. Firstly, to ensure more growth, there is a dire need to divert mindset of users who think conventional payment system more reliable and safe. Secondly, adequate and efficient infrastructural support is required to cover more people in this system. Further, E wallet marketing campaigns should be initiated to create awareness regarding the use of e wallet payment system. The solution for ensuring the development and recognition of the e wallet is not to only get an e wallet but to use for transactions. Every bankable individual must have an open wallet issued by a bank to realize the true potential of e wallets.

Moreover, lack of suitable conformity principles root a number of irregularities. The technological issues need to be addressed to make a more faultless way of using the e wallet. Another issue is the lack of acceptance, with only a small network of merchants accepting e wallet transactions and the impossibility of cash withdrawals with a semiclosed e wallet. The RBI does not allow cash out from e wallets, thereby limiting its usage only for purchase of goods and services.

\subsection{Conclusion}

The growth of e commerce and enhanced use of smart phones have revolutionized the mode of payments. The current revolution of $\mathrm{e}$ wallets has transformed the scenario of online payments owing to the ease of use, convenience and reliability. However, more awareness is required to reap full benefits of such payment technology. It requires specific guidelines by RBI, adequate infrastructure and access to common man with more safety and reliability so that the goal of financial inclusion can be achieved.

\section{References}

Abor, J. (2004). Technological Innovation and Banking in Ghana, An Evaluation of Customers' Perspective. American Academy of Financial Management, 1(3). 
72 | MANTHAN: Journal of Commerce and Management, Volume 3, Issue 1

Agimo, T. (2000, 04). Better Practice Checklist for ePayment. Australia Government Information Office. Retrieved November 14, 2015, from www.agimo.gov.au/publications/200/04/better_Practice_checklist_for_payments.

Chakraborty, A. (2015). Currency Goes Cashless, The Tribune, December, 15.

Kalakota, R., \& Whinston, A. B. (1997). Electronic Commerce; A Manager's Guide. Reading: Addison Wesley.

Pitroda S., Desai M. (2010). The March of Mobile Money - The Future of Lifestyle Management. The Mobile Wallet.

Rajgopal, K. (2012). McKinsey on Payments. Payments wave, commerce ocean: The arrival of the mobile wallet. 